\title{
Nanofibrillated Cellulose from Appalachian Hardwoods Logging Residues as Template for Antimicrobial Copper
}

\author{
Masoumeh Hassanzadeh, ${ }^{1}$ Ronald Sabo, ${ }^{2}$ Alan Rudie, ${ }^{2}$ Richard Reiner, ${ }^{2}$ \\ Roland Gleisner, ${ }^{2}$ and Gloria S. Oporto ${ }^{1}$ \\ ${ }^{1}$ School of Natural Resources, West Virginia University, Morgantown, WV 26506, USA \\ ${ }^{2}$ USDA Forest Service, Forest Products Laboratory, Madison, WI 53726-2398, USA \\ Correspondence should be addressed to Gloria S. Oporto; gloria.oporto@mail.wvu.edu
}

Received 1 March 2017; Accepted 21 May 2017; Published 19 June 2017

Academic Editor: Raul Fangueiro

Copyright (C) 2017 Masoumeh Hassanzadeh et al. This is an open access article distributed under the Creative Commons Attribution License, which permits unrestricted use, distribution, and reproduction in any medium, provided the original work is properly cited.

TEMPO nanofibrillated cellulose (TNFC) from two underutilized Appalachian hardwoods, Northern red oak (Quercus rubra) and yellow poplar (Liriodendron tulipifera), was prepared to determine its feasibility to be used as template for antimicrobial metallic copper particles. In addition, a comparison of the TNFC from the two species in terms of their morphological, chemical, thermal, and mechanical properties was also performed. The woody biomass was provided in the form of logging residue from Preston County, West Virginia. A traditional kraft process was used to produce the pulp followed by a five-stage bleaching. Bleached pulps were then subjected to a TEMPO oxidation process using the TEMPO/NaBr/ $\mathrm{NaClO}$ system to facilitate the final mechanical fibrillation process and surface incorporation of metallic copper. The final TNFC diameters for red oak and yellow poplar presented similar dimensions, $3.8 \pm 0.74 \mathrm{~nm}$ and $3.6 \pm 0.85 \mathrm{~nm}$, respectively. The TNFC films fabricated from both species exhibited no statistical differences in both Young's modulus and the final strength properties. Likely, after the TEMPO oxidation process both species exhibited similar carboxyl group content, of approximately $0.8 \mathrm{mmol} / \mathrm{g}$, and both species demonstrated excellent capability to incorporate antimicrobial copper on their surfaces.

\section{Introduction}

The production of nanofibrillated cellulose (NFC) from woody biomass has been the subject of intensive investigation in recent years, primarily, due to their unique properties including nontoxicity, biodegradability, renewability, biocompatibility, high specific surface area, high mechanical performance, and feasibility to be chemically modified [1]. These properties are opening new opportunities for NFC applications in areas that include the food industry, papermaking, pharmaceutical/medical, and composites/nanocomposites among others $[2,3]$.

NFC is nanosized cellulosic chains with dimensions less than $50 \mathrm{~nm}$ wide and lengths in the order of several micrometers $[4,5]$. NFC can be produced by applying a mechanical treatment such as high-pressure homogenization, microfluidization, grinding, and ultrasonication, to bleached pulps [3]. One important disadvantage of any mechanical treatment is its high energy consumption which has been addressed applying a preliminary pretreatment. Enzymatic and/or chemical pretreatment were demonstrated to decrease the energy demand because they will weaken the bonds that hold the cellulosic chains together making it easier to break them into nanocellulose or nanofibrillated cellulose [6]. The chemical pretreatment TEMPO-mediated oxidation process will facilitate the breakup of the fiber network and release the nanofibrils through electrostatic repulsion and osmotic effects.

TEMPO or 2,2,6,6-tetramethylpiperidine-1-oxyl is a highly stable nitroxyl radical which is used extensively in the selective oxidation of primary alcohols to corresponding aldehydes and carboxylic acids. In aqueous environments, TEMPO catalyzes the conversion of carbohydrate primary alcohols to carboxylate (COO-) functional groups in the presence of a primary oxidizing agent, for example, sodium hypochlorite $(\mathrm{NaOCl})$. In particular, wood fibers can be 
converted to individual nanofibers $3-4 \mathrm{~nm}$ wide with several microns length by TEMPO-mediated oxidation and successive mild disintegration in water $[7,8]$. During this reaction significant amounts of C6 carboxylate groups are selectively formed on each cellulose microfibril surface with minimum changes of the original crystallinity of the cellulosic material. The negative charged carboxylate groups introduced by a TEMPO-mediated oxidation will facilitate the subsequent fibrillation process due to the electrostatic forces created among microfibrils [4].

To date, some studies have compared NFC characteristics from softwood and hardwood biomass sources [5, 9-13]. Part of the available information has been focused on the evaluation of the final NFC morphology using only a mechanical fibrillation treatment [12,13]; the other part has been focused not only on the final NFC morphology but also on its carboxylic acid availability when a preliminary TEMPO-mediated oxidation process is applied to facilitate the mechanical fibrillation [5, 9-11]. To the authors' knowledge there is no previous or ongoing research regarding the use of the modified nanofibrillated surfaces to attach antimicrobial metal particles in addition to the research performed so far at West Virginia University, where we demonstrated that copper nanoparticles can be effectively synthesized on softwoods TEMPO nanofibrillated cellulose (TNFC) [14]. Likewise, the effectiveness of this TNFC-supported copper in terms of antimicrobial performance and controlled release from thermoplastic films has been also demonstrated previously [14, 15].

Currently, in the Appalachian region, there is a vast amount of low-value, low quality hardwood that can be used as feedstock for novel bioproducts. West Virginia is the third most heavily forested state in the nation. The harvesting process yields approximately 2.41 million dry tons of wood residues annually, including 1.34 million dry tones logging residue of which red oak is the predominant species, followed by yellow poplar and maple species [16]. Even though these species constitute a potential source for NFC production, to the extent of the authors' knowledge, no study in NFC preparation from any of the mentioned hardwood species has been performed to date. Only one study has been reported in West Virginia regarding the use of Appalachian underutilized hardwoods as raw material for nanocrystalline cellulose (NCC) production [17]. Consequently, the two hardwood species, red oak (Quercus rubra) and yellow poplar (Liriodendron tulipifera) which possess similar chemical composition [2], but different anatomical properties, are of interest to evaluate their properties at a nanoscale. Red oak is a ring porous hardwood with prominent and conspicuous rays and thick-walled latewood vessels. Yellow poplar is a diffuse porous hardwood, with small and solitary pores and fine rays.

The goals of this study therefore include (i) evaluating the feasibility of obtaining cellulose nanofibers from highly available underutilized logging residues from red oak and yellow poplar; (ii) comparing their changes in chemical composition, morphology, carboxyl content, and thermal and mechanical properties after TEMPO-mediated oxidation; and (iii) evaluating TNFCs feasibility to synthesize metallic copper for further antimicrobial applications.
TABLE 1: Conditions of pulping process, kappa number, and screen yield after pulping.

\begin{tabular}{lc}
\hline Kraft pulping & \\
\hline Active alkali, $\% \mathrm{Na}_{2} \mathrm{O}$ & 24 \\
Maximum temperature & $165^{\circ} \mathrm{C}$ \\
Rise to maximum temperature & $1^{\circ} / \mathrm{min}$ \\
Time at maximum temperature & $50 \mathrm{~min}$ \\
Liquor to solid ratio & 4 \\
Sulfidity & 25 \\
$H$-factor & 750 \\
Kappa number (after pulping) & RO: $13.25 ; Y P: 20$ \\
Screen yield pulping & RO: $51 \%$ YP: $52.4 \%$ \\
\hline
\end{tabular}

\section{Materials and Methods}

2.1. Materials. Northern red oak (Quercus rubra) (RO) and yellow poplar (Liriodendron tulipifera) (YP) samples were collected in 2014 at WVU Research Forest, Preston County, West Virginia, in the form of logging residue. The samples were chipped and screened. The fractions retained between 1/2 inches and $3 / 8$ inches were used for pulping.

\subsection{Methods}

2.2.1. Pulping Procedure. Small screened samples of RO and YP were oven-dried to determine the moisture content as $12 \%$. Kraft pulp from the oven-dried material was produced using a M/K System 6-L laboratory digester. The conditions for the pulping process are presented in Table 1. All pulping chemical reagents, including effective alkali, EA, $(\mathrm{NaOH}+$ $\left.(1 / 2) \mathrm{Na}_{2} \mathrm{~S}\right)$, were expressed in terms of $\mathrm{Na}_{2} \mathrm{O}$. Sulfidity was expressed as a percentage of the EA, and the expected $H$ factor was 750 . The samples were subjected to the maximum temperature of $165^{\circ} \mathrm{C}$ for $50 \mathrm{~min}$, after which the temperature was reduced rapidly. The final pulp was disintegrated by vigorous agitation, screened on a Valley flat screen (0.008inch slot), washed, and then collected in a 200 mesh screen box. The screened wet samples were used for the next step (bleaching) while some small samples were oven- and airdried for different analysis. The oven-dried pulps were characterized in terms of their lignin content via Kappa number determination. The Kappa numbers of the two species were determined by measuring the consumption of potassium permanganate according to T236 cm-85 standard method. The percentage of lignin was estimated using the following equation:

$$
\text { Lignin }(\%)=\text { Kappa number } \times 0.15 \text {. }
$$

2.2.2. Bleaching. A five-stage bleaching sequence DEpDEpD was performed, where $\mathrm{D}$ denotes chlorine dioxide and $\mathrm{Ep}$ represents peroxide reinforced alkaline extraction. The pulps were thoroughly washed between stages. After the completion of all stages, the fibers were washed and oven-dried. Table 2 shows the conditions of the bleaching processes. 
TABLE 2: Conditions of bleaching process.

\begin{tabular}{|c|c|c|c|c|c|}
\hline Stage & $\mathrm{D}$ & $\begin{array}{c}\text { Ep } \\
\text { (alkaline extraction stage 1) }\end{array}$ & $\begin{array}{c}\mathrm{D} \\
\text { (second chlorine dioxide) }\end{array}$ & Ep & $\mathrm{D}$ \\
\hline Chemical charge & $\begin{array}{c}\mathrm{CLO}_{2}(1.7 \%) \\
\mathrm{H}_{2} \mathrm{SO}_{4}(0.2 \%)\end{array}$ & $\begin{array}{c}\mathrm{NaOH}(2 \%) \\
\mathrm{H}_{2} \mathrm{O}_{2}(0.38 \%)\end{array}$ & $\mathrm{ClO}_{2}(0.8 \%)$ & $\begin{array}{c}\mathrm{H}_{2} \mathrm{O}_{2}(0.197 \%) \\
\mathrm{NaOH}(1 \%)\end{array}$ & $\mathrm{ClO}_{2}(0.3 \%)$ \\
\hline Pulp consistency & $10 \%$ & $10 \%$ & $10 \%$ & $10 \%$ & $10 \%$ \\
\hline End $\mathrm{pH}$ & 2.5 & 11 & 3.5 & 11 & \\
\hline Temperature & $70^{\circ} \mathrm{C}$ & $70^{\circ} \mathrm{C}$ & $70^{\circ} \mathrm{C}$ & $70^{\circ} \mathrm{C}$ & $70^{\circ} \mathrm{C}$ \\
\hline Time & $45 \mathrm{~min}$ & $60 \mathrm{~min}$ & $80 \mathrm{~min}$ & $130 \mathrm{~min}$ & $60 \mathrm{~min}$ \\
\hline
\end{tabular}

D: chlorine dioxide; E: peroxide reinforced alkaline extraction.

TABLE 3: Chemical characterization of untreated wood (raw) and bleached pulps (B).

\begin{tabular}{lcccc}
\hline Sample & Cellulose $\%$ & Hemicellulose $\%$ & Klason lignin (\%) & ASL $^{*}(\%)$ \\
\hline Raw $_{\text {RO }}$ & $53.8 \pm 0.6$ & $19.34 \pm 0.8$ & $22.5 \pm 0.2$ & 4.41 \\
Raw $_{\text {YP }}$ & $56.8 \pm 0.7$ & $17.7 \pm 1.1$ & $22.3 \pm 0.5$ & 3.30 \\
$B_{\text {RO }}$ & $78.4 \pm 1.6$ & $20.5 \pm 2.4$ & $1.1 \pm 0.7$ & 0.16 \\
$B_{\text {YP }}$ & $81.5 \pm 1.7$ & $17.6 \pm 2.1$ & $1.1 \pm 0.6$ & 0.15 \\
\hline
\end{tabular}

*ASL: acid soluble lignin was measured just one time.

2.2.3. TEMPO-Mediated Oxidation. Approximately $30 \mathrm{~g}$ of oven-dry basis bleached pulp was add to $3 \mathrm{~L}$ of water that contained TEMPO (0.016 g per g pulp) and sodium bromide $(0.1 \mathrm{~g} / \mathrm{g}$ pulp). The reaction was started by adding $\mathrm{NaClO}$ solution (5.0 mmol $\mathrm{NaClO}$ per $\mathrm{g}$ of pulp) with stirring at $500 \mathrm{rpm}$ at room temperature. The $\mathrm{pH}$ was maintained at 10 by adding $0.5 \mathrm{M} \mathrm{NaOH}$ using a $\mathrm{pH}$ stat until no $\mathrm{NaOH}$ consumption was observed. Additional $\mathrm{NaClO}$ was add to each sample as long as no changes in $\mathrm{pH}$ were observed. The TEMPO-oxidized cellulose was thoroughly washed with water by filtration and stored at $4^{\circ} \mathrm{C}$ before homogenization [1]. The yield has been measured based on weight of dried final material and weight of diluted samples which results in approximately $90 \%$ for both TOWP samples.

Samples of each species were air-dried and then used to characterize the degree of polymerization (DP) and carboxylic acid group determination. The rest of the TEMPOoxidized sample was diluted to $1 \%$ solid content, before homogenization. Mechanical fibrillation was performed by passing the samples twice through an M-110EH-30 Microfluidizer (Microfluidics, Newton, MA). In the first step, the material passed through a $200 \mu \mathrm{m}$ chamber and in the second step the suspension passed through $200-$ and $87-\mu \mathrm{m}$ chambers in series.

2.2.4. Chemical Analysis. Samples from kraft and bleached pulps were dried and ground in a Willey mill to pass a 20 mesh screen (model number 2, Arthur H. Thomas co). These samples along with untreated samples were used for the chemical composition analyses that included Klason lignin, acid soluble lignin, and hemicellulose and cellulose determination. High performance anion exchange chromatography (Dionex ICS-3000 system) and the procedure developed by Davis (1998) [18] were used for the carbohydrate determination. Lignin was determined based on the amount of sulfuric acid-insoluble Klason lignin, in accordance with
TABLE 4: Viscosity and degree of polymerization of bleached samples and samples after TEMPO oxidation process (TOWP). Note. TOWP: TEMPO-oxidized wood pulp.

\begin{tabular}{lcc}
\hline Sample(s) & Viscosity $(\mathrm{mPa} \mathrm{s})$ & DP \\
\hline Bleached $_{(\mathrm{RO})}$ & $19.4 \pm 0.4$ & $3152-3300$ \\
Bleached $_{(\mathrm{YP})}$ & $10.9 \pm 0.2$ & $1666-1736$ \\
TOWP $_{(\mathrm{RO})}$ & $2.9 \pm 0.2$ & $361-421$ \\
TOWP $_{(\mathrm{YP})}$ & $2.4 \pm 0.1$ & $302-332$ \\
\hline
\end{tabular}

the standard of the Technical association of pulp and paper industry (TAPPI) TAPPI standards-T222 om 88. The results are presented in Table 3. All the analyses, with the exception of acid soluble lignin, were performed in duplicate.

2.2.5. Determination of Intrinsic Viscosity and Degree of Polymerization. Viscosity of the resulting nanofibrillated cellulose was measured according to TAPPI Standard Method T230 om-99. Oven-dried cellulosic solids of $0.1 \mathrm{~g}$ were dispersed in $10 \mathrm{~mL}$ distilled water and then added to $10 \mathrm{~mL}$ of $1 \mathrm{M}$ cupriethylenediamine solution ( $0.5 \%$ solid concentration). The viscosity of the resultant solution was determined with a capillary viscometer. The degree of polymerization (DP) was estimated by the following equation:

$$
\mathrm{DP}=120 \times[\eta]^{1.11},
$$

where $\eta$ is the measured viscosity; the results are presented in Table 4.

2.2.6. Carboxyl Content of the Pulp. Determination of carboxyl content of the samples before and after the TEMPOmediated oxidation process was performed according to T237 om-88, modified as indicated below to account for the high acid content of the fiber with some reagent concentration 


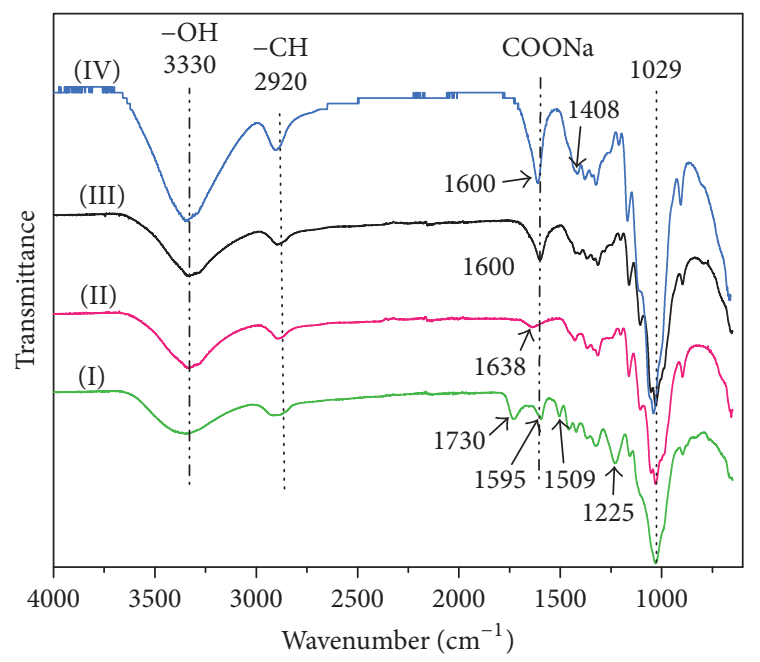

(a)

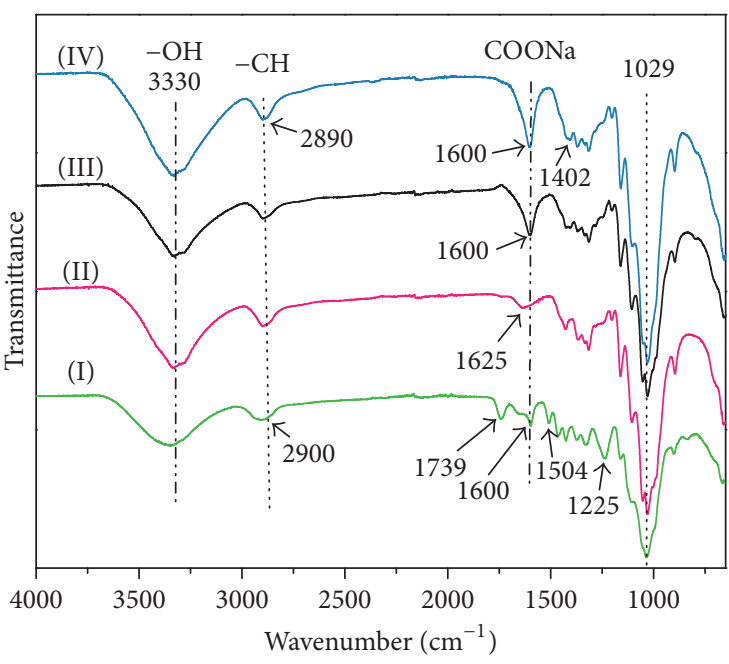

(b)

FIGURE 1: (a) FTIR spectra of red oak: (I) raw material, (II) bleached, (III) tempo-oxidized wood pulp (TOWP), and (IV) TEMPO-oxidized cellulose nanofibers (TNFC). (b) FTIR spectra of yellow poplar: (I) raw material, (II) bleached, (III) tempo-oxidized wood pulp (TOWP), and (IV) TEMPO-oxidized cellulose nanofibers (TNFC).

TABLE 5: Carboxylic contents of Red oak and Yellow poplar species for bleached and TEMPO-oxidized samples (TOWP).

\begin{tabular}{lc}
\hline Samples & COOH $(\mathrm{mmol} / \mathrm{g})$ \\
\hline Bleached $_{\mathrm{RO}}$ & 0.05 \\
Bleached $_{\mathrm{YP}}$ & 0.07 \\
TOWP $_{\mathrm{RO}}$ & 0.82 \\
TOWP $_{\mathrm{YP}}$ & 0.80 \\
\hline
\end{tabular}

modifications. The pulps were converted to the acid form by soaking them in $0.01 \mathrm{M} \mathrm{HCl}$ and then washing with deionized water. This acidified pulp was reacted with a standardized $0.1 \mathrm{M} \mathrm{NaHCO}_{3}$ with $0.25 \mathrm{M} \mathrm{NaCl}$ solution. The amount of residual $\mathrm{NaHCO}_{3}$ was determined by titration with $0.1 \mathrm{M}$ $\mathrm{HCl}$, to a methyl red endpoint. The carboxyl content was calculated in milliequivalents (meq) per $100 \mathrm{~g}$ of oven-dry pulp and then converted to $\mathrm{mmol} / \mathrm{g}$ and the results are presented in Table 5.

2.2.7. Fourier Transform Infrared Spectroscopy (FTIR). Fourier transform infrared spectra were recorded for the raw material, bleached pulps, TEMPO-oxidized pulps, and the final TEMPO nanofibrillated cellulose (TNFC) samples using a Perkin-Elmer Spectrum 2000 FTIR spectrometer. The samples were analyzed from 600 to $4,000 \mathrm{~cm}^{-1}$. The spectrum was obtained from dry samples using 16 scans at a $4 \mathrm{~cm}^{-1}$ resolution and a $1 \mathrm{~cm}^{-1}$ interval at room temperature. The results are presented in Figure 1.

2.2.8. X-Ray Diffraction (XRD) Characterization. X-ray diffraction (XRD) analysis was performed on the raw material, TEMPO-oxidized pulps, and the final TEMPO nanofibrillated cellulose (TNFC) samples. The analysis was performed
TABLE 6: Crystallinities of raw material, TEMPO-oxidized wood pulp (TOWP), and TEMPO-oxidized cellulose nanofibers (TNFC).

\begin{tabular}{lc}
\hline Sample & Degree of crystallinity (\%) \\
\hline Raw $_{\mathrm{RO}}$ & $37.0 \pm 3.26$ \\
Raw $_{\mathrm{YP}}$ & $34.4 \pm 2.5$ \\
TOWP $_{\mathrm{RO}}$ & $61.7 \pm 1.66$ \\
TOWP $_{\mathrm{YP}}$ & $59.85 \pm 2.2$ \\
TNFC $_{\mathrm{RO}}$ & $39.3 \pm 0.9$ \\
TNFC $_{\mathrm{YP}}$ & $39.4 \pm 0.5$ \\
\hline
\end{tabular}

on a X-ray diffractometer (PANalytical X'Pert Pro XRD) in the range of $10^{\circ}$ to $40^{\circ} 2 \theta$. Cu- $k \alpha 18047.2 \mathrm{eV}$ source and a maximum X-ray power of $45 \mathrm{kV}$ and $40 \mathrm{~mA}$ were used. The crystallinity index (CI) after the different treatments was determined using the peak height method and calculated by the Segal empirical method [19] after subtraction of the background signal:

$$
\mathrm{CI}(\%)=\frac{I_{200}-I_{\mathrm{am}}}{I_{200}} \times 100 \%,
$$

where $I_{200}$ is the peak intensity corresponding to crystalline cellulose $I$ at $2 \theta=22.6^{\circ}$ and $I_{\mathrm{am}}$ is the intensity minimum between the 200 and 110 peaks $\left(2 \theta=18^{\circ}\right)$.

The results are presented in Table 6 and Figure 2.

2.2.9. Thermogravimetric Analysis (TGA). Thermogravimetric analysis was performed for the raw material and the final TEMPO nanofibrillated cellulose (TNFC) using 4-6 mg sample. The data was obtained using a TA Q50 thermogravimetric analyzer (Delaware, USA). The temperature was set from $25^{\circ} \mathrm{C}$ to $600^{\circ} \mathrm{C}$ at a heating rate of $10^{\circ} \mathrm{C} / \mathrm{min}$ under a nitrogen atmosphere at a flow rate of $20 \mathrm{~mL} / \mathrm{min}$. The results of this analysis are presented in Table 7 and Figure 3. 
TABLE 7: Onset degradation temperature $\left(T_{\text {onset }}\right)$, maximum thermal degradation temperature $\left(T_{\max }\right)$, maximum weight loss $\left(\mathrm{WL} \mathrm{L}_{\max }\right)$, and CY (char yield) (\%) (char residue after $\left.575^{\circ} \mathrm{C}\right)$.

\begin{tabular}{|c|c|c|c|c|c|c|}
\hline \multirow{2}{*}{ Samples } & \multirow{2}{*}{$T_{\text {onset }}\left({ }^{\circ} \mathrm{C}\right)$} & \multicolumn{2}{|c|}{ Stage I } & \multicolumn{2}{|c|}{ Stage II } & \multirow{2}{*}{ CY (\%) } \\
\hline & & $T_{\max }\left({ }^{\circ} \mathrm{C}\right)$ & $\mathrm{WL}_{\max }\left(\% /{ }^{\circ} \mathrm{C}\right)$ & $T_{\max }\left({ }^{\circ} \mathrm{C}\right)$ & $\mathrm{WL}_{\max }\left(\% /{ }^{\circ} \mathrm{C}\right)$ & \\
\hline $\mathrm{Raw}_{\mathrm{RO}}$ & 304.5 & 285 & 0.45 & 358 & 1.12 & 14.0 \\
\hline $\mathrm{Raw}_{\mathrm{YP}}$ & 312 & - & - & 366 & 1.17 & 13.4 \\
\hline $\mathrm{TNFC}_{\mathrm{RO}}$ & 224 & 234 & 0.58 & 288 & 0.68 & 20.0 \\
\hline $\mathrm{TNFC}_{\mathrm{YP}}$ & 225 & 232 & 0.6 & 290 & 0.7 & 19.5 \\
\hline
\end{tabular}

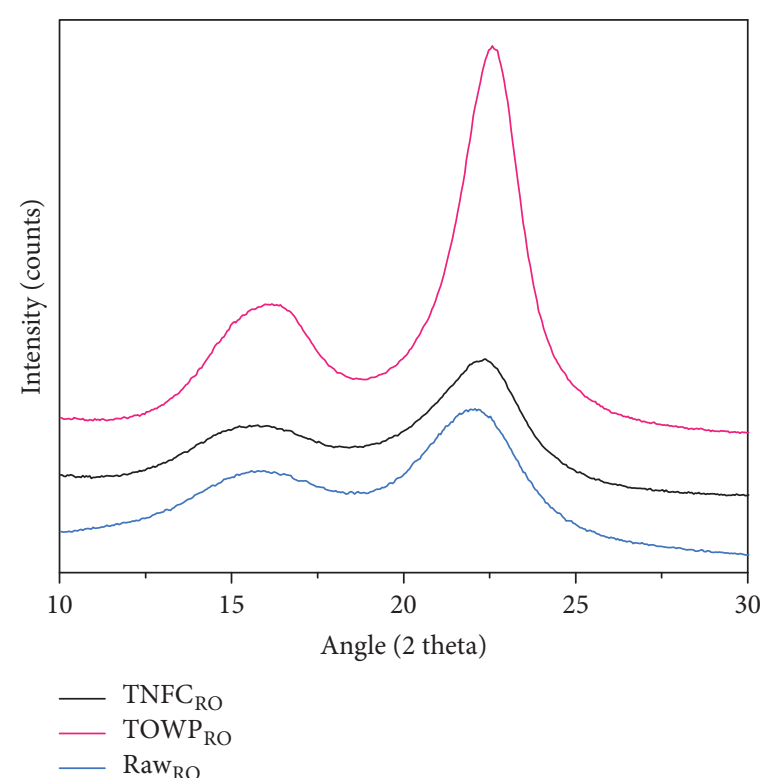

(a)

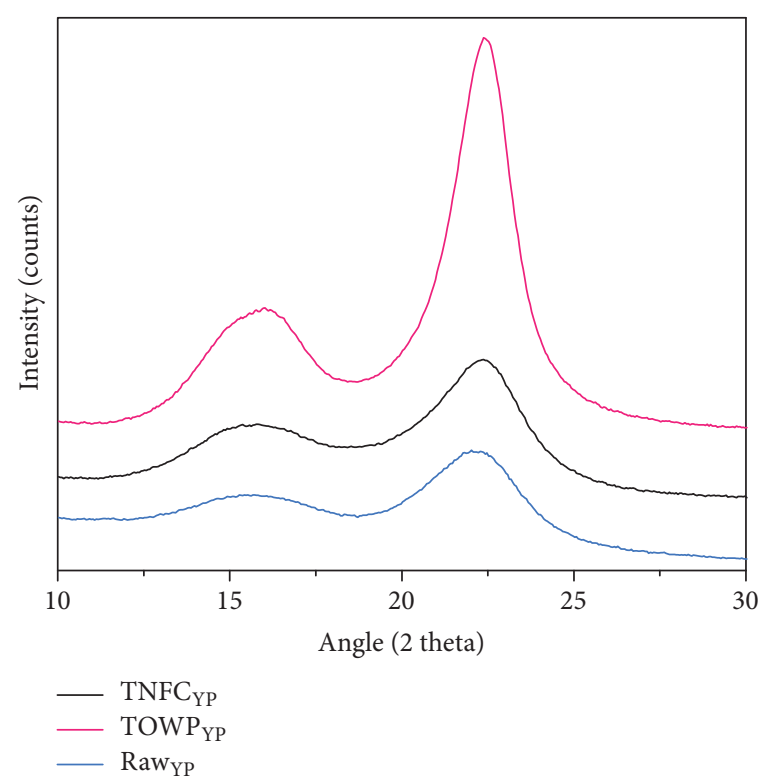

(b)

FIGURE 2: X-ray diffraction patterns of (a) $\mathrm{Raw}_{\mathrm{RO}}$, TOWP $\mathrm{RO}_{\mathrm{RO}}$, and $\mathrm{TNFC}_{\mathrm{RO}}$; (b) $\mathrm{Raw}_{\mathrm{YP}}, \mathrm{TOWP}_{\mathrm{YP}}$, and $\mathrm{TNFC}_{\mathrm{YP}}$.

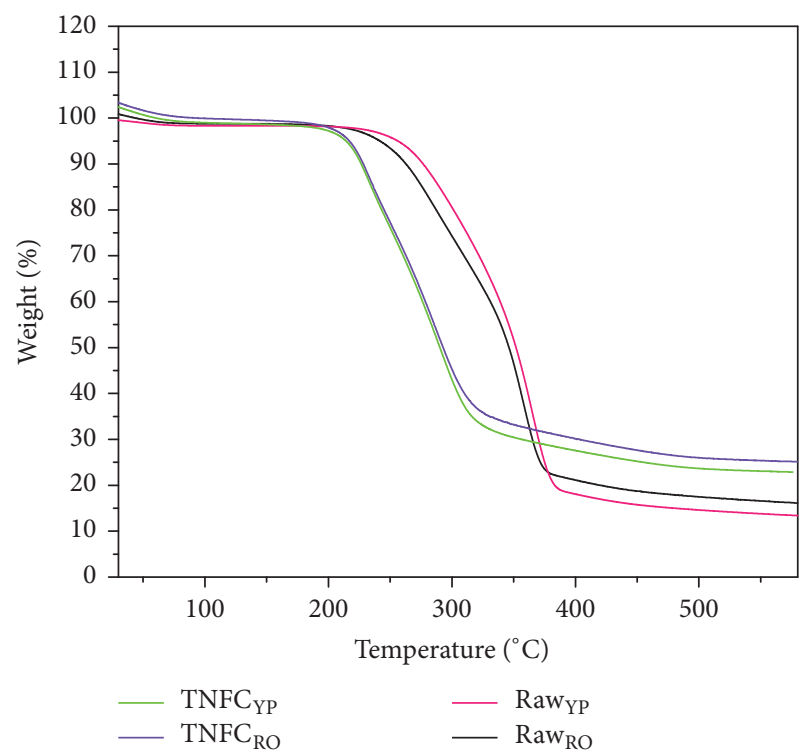

(a)

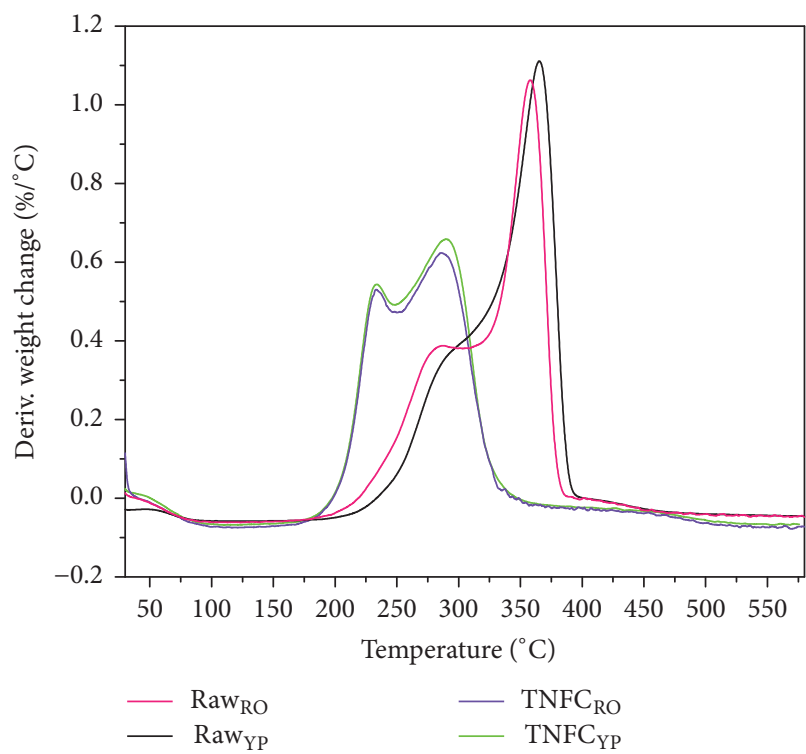

(b)

FIGURE 3: Thermogravimetric (TGA (a)) and the corresponding derivative thermogravimetric (DTG) (DTG (b)) curves of the raw material and TEMPO-oxidized cellulose nanofibers (TNFC). 
2.2.10. Scanning Electron Microscopy (SEM). Scanning electron microscopy (SEM) was used to evaluate the effect of mechanical fibrillation on the samples morphology. TEMPOoxidized wood pulp (TOWP) and TEMPO nanofibrillated cellulose (TNFC) were freeze-dried after a preliminary solvent exchange process using ethanol and tert-butanol [20]. Freeze drying was conducted on a VirTis Genesis Freeze Dryer (Warminster, PA, USA) at $-40^{\circ} \mathrm{C}$ for 1 week. The morphological analyses of the samples were performed using a Hitachi S-4700 FESEM-EDX. Before the FESEM-EDX analyses, all the samples were coated with gold-palladium using a sputtering process to provide adequate conductivity. The diameter of different samples after bleaching and TEMPO oxidation was measured and calculated using the ImageJ Manipulation Program [21] for at least 30 fibers for each sample. Results are presented in Figure 4.

\subsubsection{Transmission Electron Microscope (TEM). For TEM} analysis TNFC samples of RO and YP were used as their original undiluted suspension form. Undiluted TNFC suspensions were deposited on a glow-discharged copper grid with formvar and carbon film (400 mesh) for 5 min and then rinsed thoroughly using a $1 \%$ aqueous uranyl acetate stain followed by blotting dry. Samples were imaged using Philips CM-100 TEM (Philips/FEI Corporation, Eindhoven, Holland) operated at $100 \mathrm{kV}$, spot $3,200 \mu \mathrm{m}$ condenser aperture, and $70 \mu \mathrm{m}$ objective aperture. The images were captured in digital form directly on the microscope using Gatan Orius SC200-1 2 Mpixel CCD camera (Gatan, Inc., Pleasanton, CA) with 19k, $46 \mathrm{k}$, and $92 \mathrm{k}$ magnification. The diameter of different NFCs was measured and calculated from TEM images using the Image J Manipulation Program [21] for at least 50 nanofibers in each sample. The results are presented in Figure 5.

2.2.12. Preparation and Characterization of TNFC Films. TNFC hydrogel films were prepared by filtering TNFC suspensions which were dried afterwards. The filtration was performed by first diluting the TNFC suspension to $0.2 \%$ solid by weight with reverse-osmosis-treated water. Following the dilution, the suspensions were filtered using a 142-mm Millipore ultrafiltration system (Millipore Corporation, Billerica, MA, USA) under $0.55 \mathrm{MPa}$ of air pressure. Omnipore TM filter membranes with a pore size of $0.1 \mu \mathrm{m}$ (JVWP14225, JV, Millipore Corporation, USA) were supported on filter paper in the ultrafiltration system. The wet films (hydrogels) were peeled from the membrane, processed, stacked, and placed between an assembly of waxy coated papers, absorbent blotter paper, and two metal caul plates. The assembly was air-dried at room temperature for $24 \mathrm{~h}$ and then oven-dried at $60^{\circ} \mathrm{C}$ for $8 \mathrm{~h}$ under a load of approximately $250 \mathrm{~N}$. The blotter and filter papers were replaced several times over the first $24 \mathrm{~h}$ to minimize wrinkling of the films [22].

The tensile strength of different NFC films was tested using an Instron 5865 universal material testing apparatus (Instron Engineering Corporation, MA, USA) with a $500 \mathrm{~N}$ load cell, according to ASTM D638-10. The specimens were cut according to ASTM D638-10 type V dog bone shape using a special die (Qualitest, FL, USA) and were subsequently conditioned at $50 \% \mathrm{RH}$ and $23^{\circ} \mathrm{C}$ for at least 1 week prior to testing, also at $50 \% \mathrm{RH}$ and $23^{\circ} \mathrm{C}$. The specimens were preloaded with a $5 \mathrm{~N}$ force to remove slack and the tests were performed with a crosshead speed of $1 \mathrm{~mm} / \mathrm{min}$. At least 6 specimens were tested for each sample. A LX 500 laser extensometer (MTS Systems Corporation, MN, USA) was used to determine the displacement with sampling frequency of $10 \mathrm{~Hz}$. The laser recorded the displacement between two strips of reflective tape initially placed $8 \mathrm{~mm}$ apart on the neckeddown region of the dog bone specimens. Strain was calculated from the displacement and initial gage length [23]. The stressstrain curves were fit to a hyperbolic tangent and the tensile modulus was taken as the slope of the fit curve at zero strain. The statistical significance was determined using a two-tailed unpaired Student's $t$-test and $p$ value $<0.05$ was considered statistically significant. The maximum tensile strength and the corresponding tensile modulus are presented in Figure 6.

\subsubsection{Preparation of Hybrid TNFC and Copper Nanoparticles.} The hybrid TNFC-metallic copper particles were prepared according to Jiang et al., 2016 [14], and Zhong et al., 2015 [15]. Upon dispersing the hybrid materials into deionized water, they were dried using a preliminary solvent exchange process with ethanol/tert-butanol and then freeze-dried as described by Zhong et al., 2015 [20].

2.2.14. Copper Determination on TNFC from Red Oak and Yellow Poplar. Copper determination of TNFC-metallic copper particles was conducted using Energy-Dispersive X-ray (EDX) analysis and the results are presented in Table 9. The morphological analysis of the TNFC-metallic copper particles from red oak and yellow poplar was performed using a Hitachi S-4700 FE-SEM; the samples were previously coated with gold-palladium using a sputtering process to provide adequate conductivity. An example of the final morphology of these samples with the presence of copper crystals is presented in Figure 7.

\section{Results and Discussion}

3.1. Chemical Analysis. The contents of the primary constituents (cellulose, hemicellulose, and lignin) of the untreated woody samples and bleached pulps are presented in Table 3. According to these results, bleached samples of YP contained slightly more cellulose content and less hemicellulose than RO. For RO and YP, carboxylic contents were nearly identical (Table 5) and might be one reason indicating that the difference in hemicellulose content between two samples is negligible to have an effect on carboxyl content. It has also been reported that high content of hemicelluloses facilitates the release of nanofibrils during the mechanical treatment of the pulp [24]; however, as mentioned above, the difference in hemicellulose content in RO and YP does not look significant based on results of carboxyl contents.

In terms of lignin, no differences between RO and YP were determined for both untreated and bleached pulps. The kappa number (KN) of the kraft pulp was 13.25 and 20 giving the lignin percentage of 1.72 and 2.6 for RO and YP 


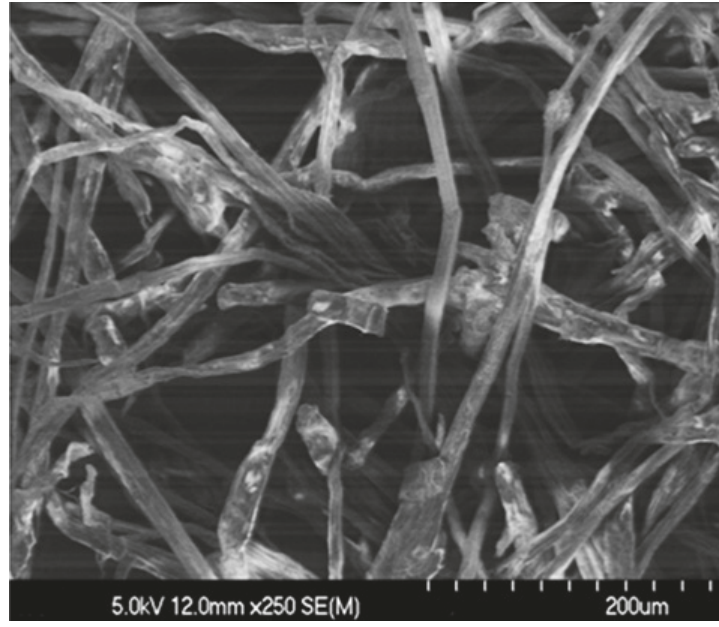

(a)

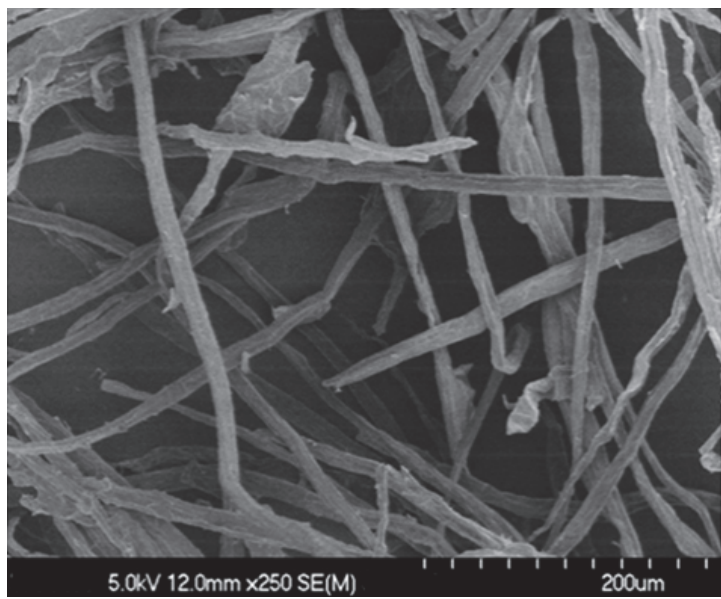

(c)

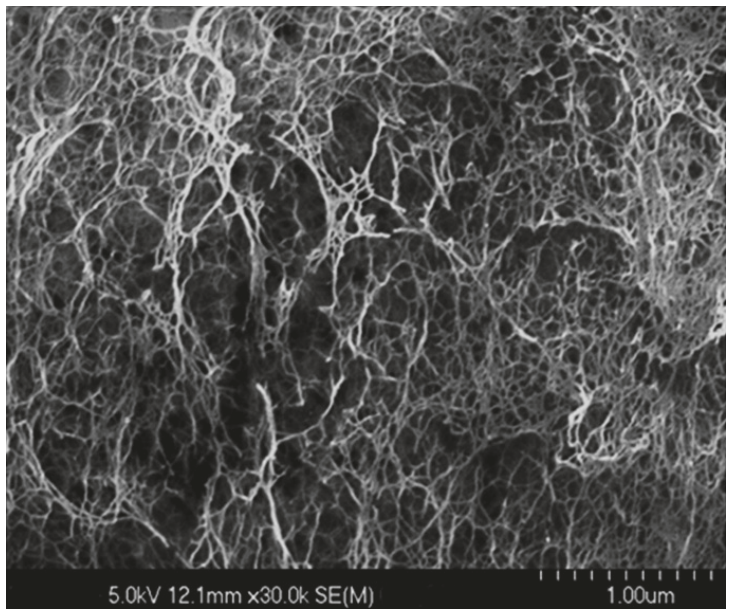

(e)

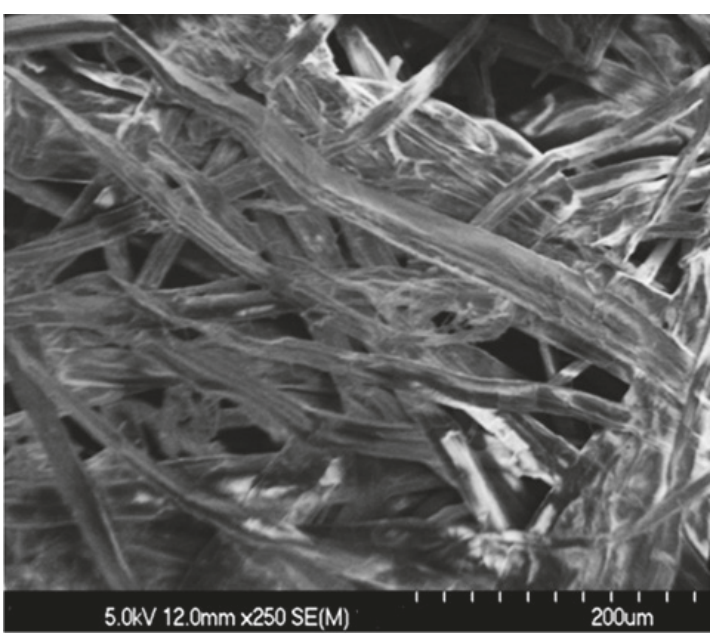

(b)

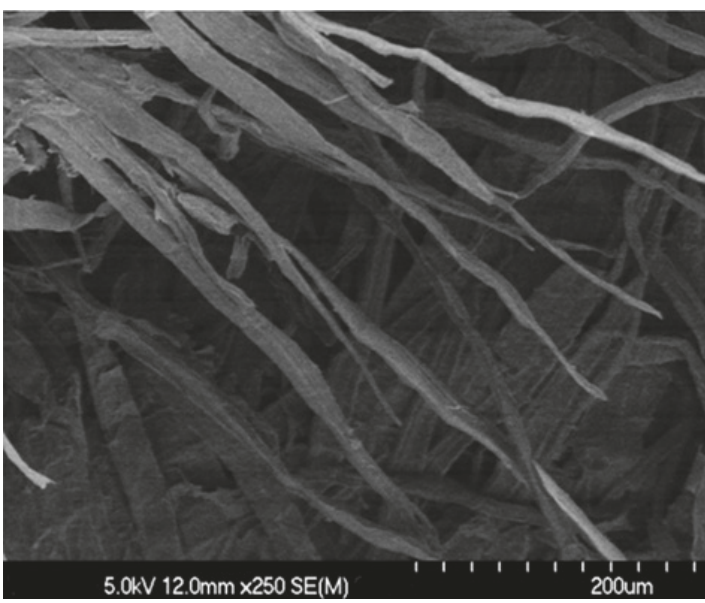

(d)

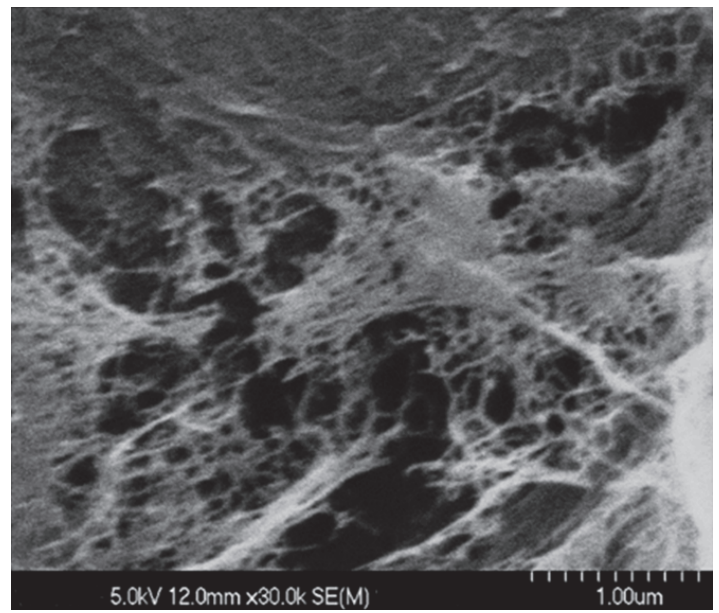

(f)

FIGURE 4: FE-SEM micrographs of the bleached RO (a) and YP (b); TEMPO-oxidized wood pulp (TOWP) of RO (c) and YP (d); TEMPO nanofibrillated cellulose (TNFC) of RO (e) and YP (f) samples after a solvent exchange (E/tert-B-FD treatment) followed by freeze drying. 


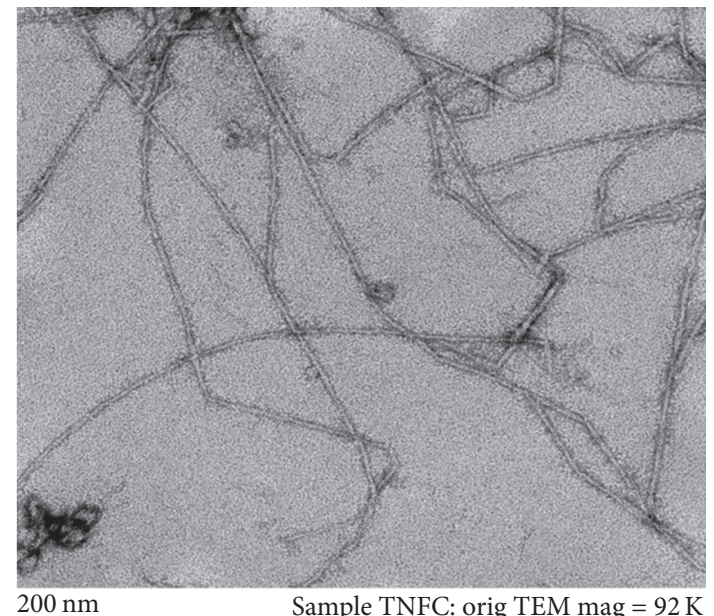

(a)

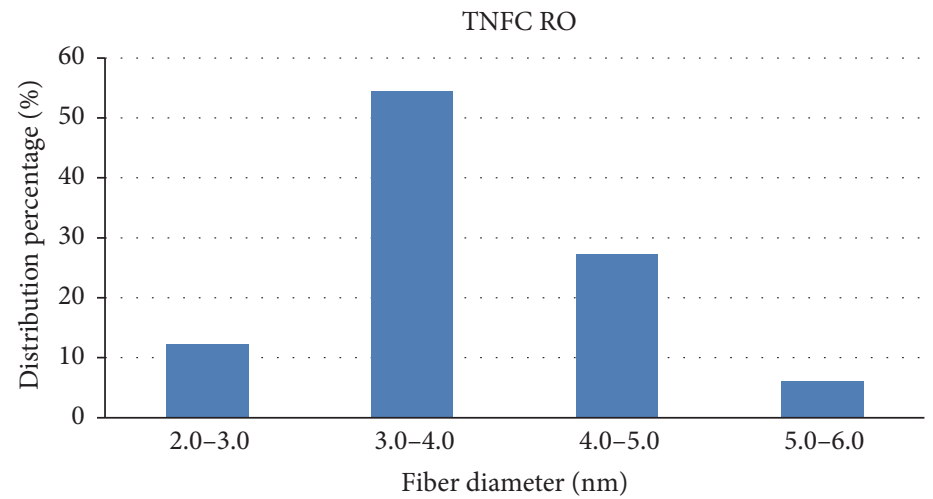

(c)

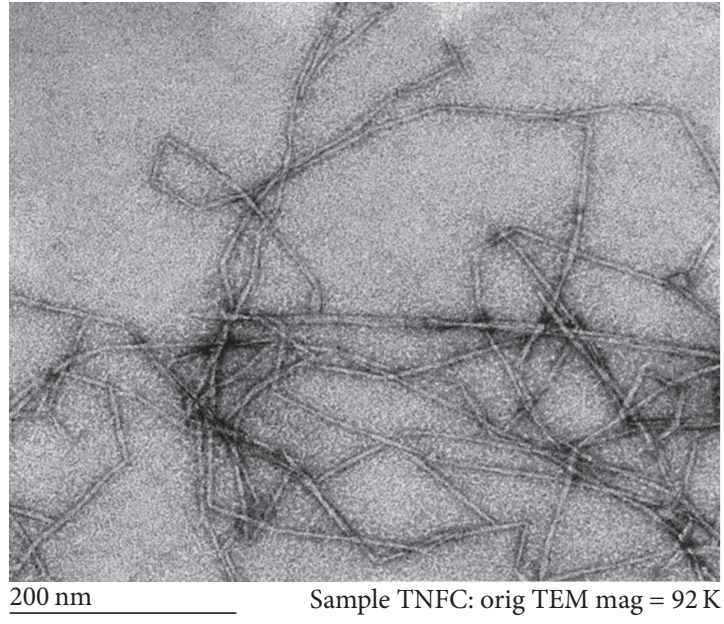

(b)

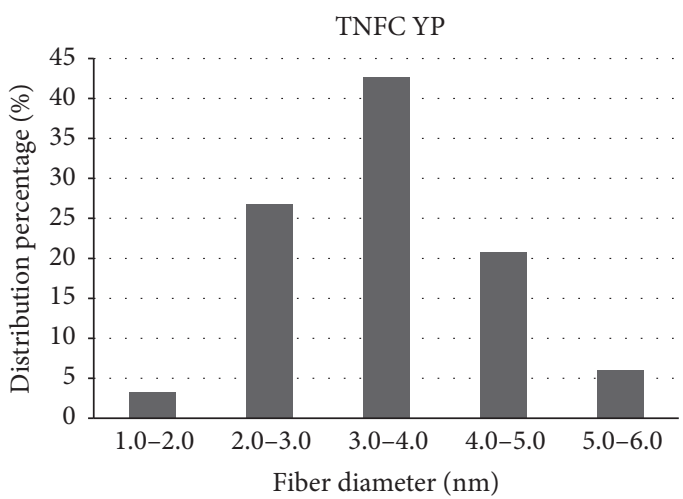

(d)

FIGURE 5: TEM images of $\operatorname{TNFC}_{\mathrm{RO}}(\mathrm{a})$ and $\mathrm{TNFC}_{\mathrm{YP}}(\mathrm{b})$ and their size distribution properties: (c) RO; (d) YP.

after the kraft pulping, respectively. The kappa number varies according to the wood species and delignification procedure during pulping [25].

3.2. Degree of Polymerization (DP). The degree of polymerization as a function of the viscosity of bleached and TEMPOoxidized wood pulp (TOWP) from RO and YP is presented in Table 4. The viscosity is an indirect measurement of the cellulose polymer chain length and can be used to indicate chemical degradation of the pulps due to chemical or mechanical treatments.

The viscosity and correspondent DP result are higher for RO bleached and TOWP samples. This result might be related to the previous difference in terms of the hemicellulose content. The TEMPO-mediated oxidation and especially the use of $\mathrm{NaClO}$ inevitably lead to depolymerization of the starting material in both samples of RO and YP but showed a slight reduction in YP samples.

3.3. Carboxyl Content. The carboxylic group content was determined for RO and YP bleached pulps and for the RO and YP TEMPO-oxidized samples. As presented in Table 5 the carboxylic group increased from $0.05-0.07 \mathrm{mmol} / \mathrm{g}$ for the bleached pulps to $0.80-0.82 \mathrm{mmol} / \mathrm{g}$ after the oxidation process. The increase in the carboxylic content after the TEMPOmediated oxidation process was similar for both hardwood species.

3.4. FTIR Spectroscopy Analysis. The analysis of functional groups through FTIR is presented in Figure 1(a) for RO and Figure 1(b) for YP, where (I) corresponds to the initial woody raw material; (II) is the bleached samples; (III) is the TEMPO-oxidized samples (TOWP); and (IV) corresponds to the TEMPO nanofibrillated material (TNFC).

The absorption peaks at $3300 \mathrm{~cm}^{-1}$ and $2920-2800 \mathrm{~cm}^{-1}$ were attributed to hydrogen bonded hydroxyl $(\mathrm{OH})$ groups of cellulose and absorbed water and aliphatic saturated $\mathrm{C}-\mathrm{H}$ stretching vibration, respectively [26-30]. These peaks increased in intensity after bleaching and TEMPO oxidation.

The bands present at 1730 and $1739 \mathrm{~cm}^{-1}$ which are possible to observe only for the untreated raw material for both $\mathrm{RO}$ and $\mathrm{YP}$ can be attributed to $\mathrm{C}=\mathrm{O}$ stretching of the acetyl and uronic ester groups of hemicellulose or the ester linkage of carboxylic groups of ferulic and p-coumaric acids of lignin and/or hemicellulose [31,32]. This band was no longer present in the FTIR spectra of RO and YP after bleaching 


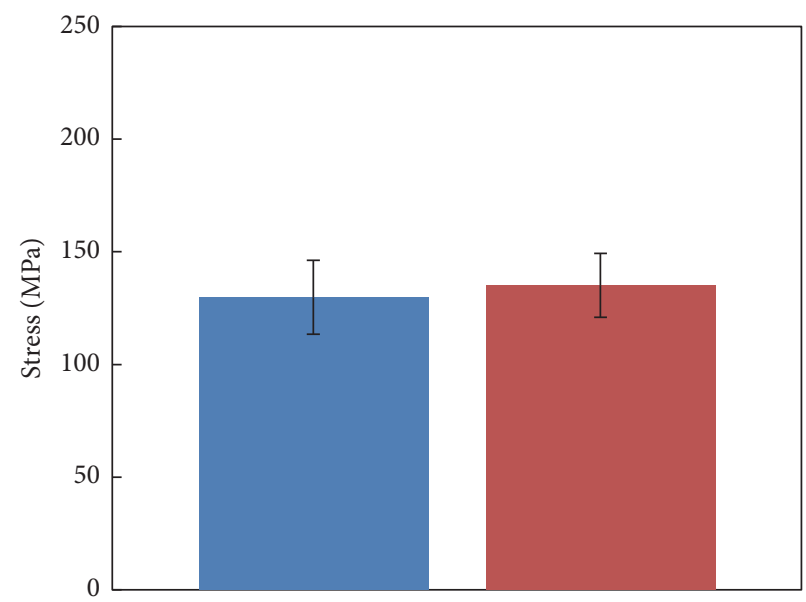

- RO

- YP

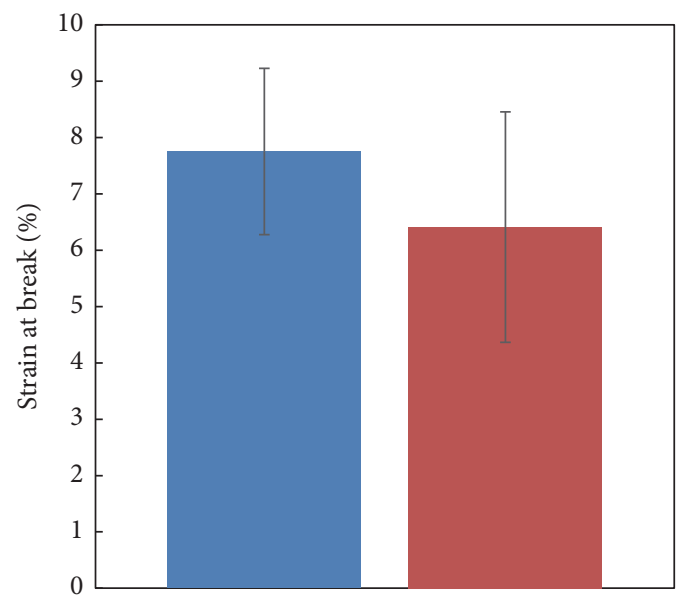

- RO

口 YP

(a)

(b)

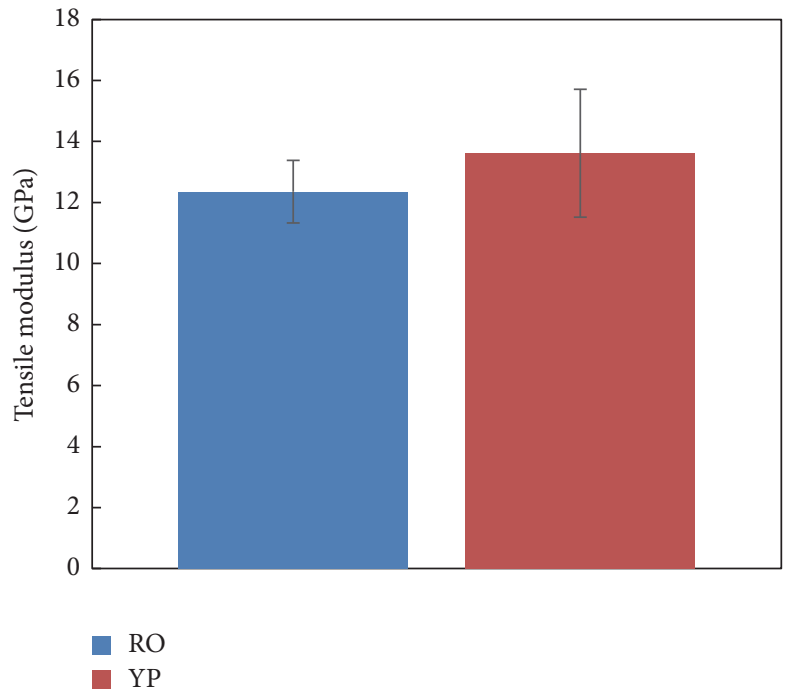

(c)

FIGURE 6: Main tensile properties of NFC films prepared from cellulose nanofibrils of RO (RO) and YP (YP). (a) Stress; (b) strain at break; (c) tensile modulus.
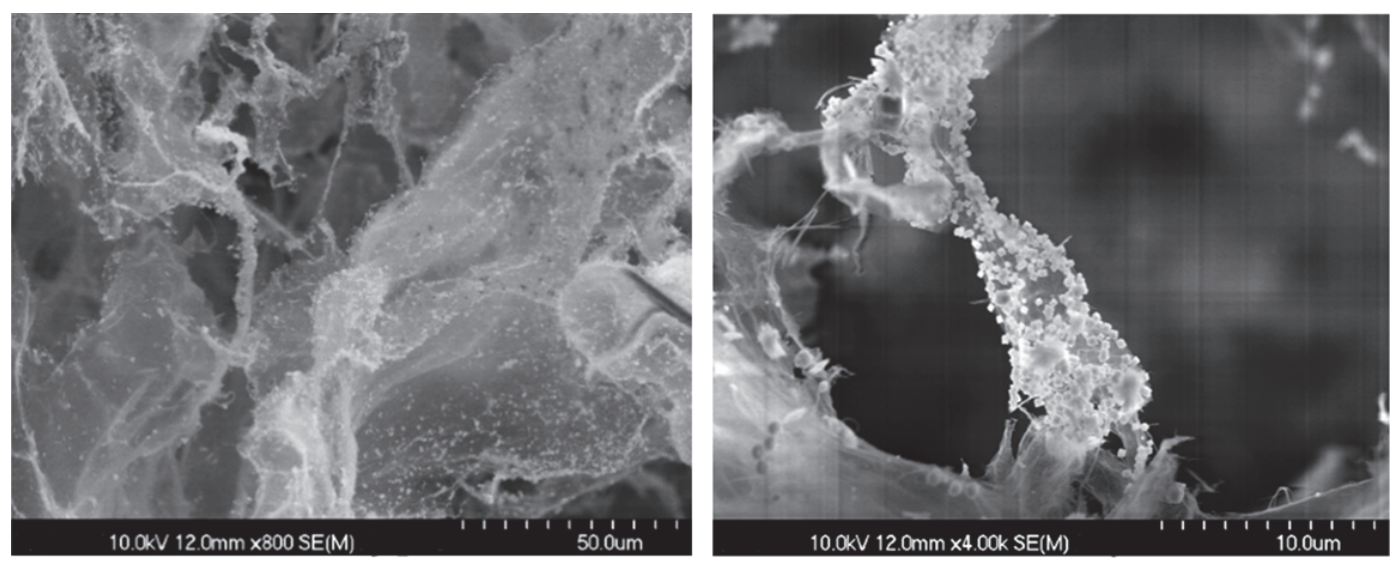

FIGURE 7: SEM images of dried $\mathrm{TNFC}_{\mathrm{RO}}$ after the treatment with copper sulphate and reducing agent sodium borohydride $\left(\mathrm{TNFC} \mathrm{RO}^{-\mathrm{Cu}}\right)$. 
and subsequent TEMPO oxidation treatments. The disappearance of this band is largely due to the removal of hemicellulose and lignin from RO and YP fibers during the chemical extraction $[31,33]$. The peaks at $1,509-1,504 \mathrm{~cm}^{-1}$ in the spectra of raw samples of $\mathrm{RO}$ and $\mathrm{YP}$ represent the $-\mathrm{C}=\mathrm{C}-$ stretch of the aromatic rings of lignin $[32,34]$. The lower amount of this peak in the treated samples is attributed to the removal of lignin during chemical procedures.

Two strong absorption bands at around 1638-1600 and $1412-1402 \mathrm{~cm}^{-1}$, which correspond to carbonyl groups $-\mathrm{C}=\mathrm{O}$, are present in both spectra in response to the TEMPOmediated oxidation process. As expected after the TEMPO oxidation process hydroxyl groups at the C6 position of cellulose molecules were converted to sodium carboxylate. The intensity of $-\mathrm{C}=\mathrm{O}$ peaks for both hardwood species presents the following trend: TNFC $=$ TOWP $>$ bleached $>$ raw material individually, whereas, comparing RO and YP graphs, these areas have shown same intensity.

The peaks observed in the spectra of the fibers around $1225 \mathrm{~cm}^{-1}$ are due to the $\mathrm{C}-\mathrm{O}$ stretching of the aryl group in lignin [35]. Disappearance of this peak from the spectra of the bleached pulp fibers as well as from those of the nanofibers is explained by the removal of lignin due to chemical treatments.

The stretching of $\mathrm{C}-\mathrm{O}$ and $\mathrm{O}-\mathrm{H}$ and bending vibration of the $\mathrm{C}-\mathrm{O}-\mathrm{C}$ pyranose ring in cellulose molecules $[36,37]$ can be observed as peaks around $1070-1010 \mathrm{~cm}^{-1}$ for all samples. The peak at $1029 \mathrm{~cm}^{-1}$ for both hardwood species seems to be much higher for TNFC in following the trend TNFC > TOWP $>$ bleached $>$ raw material in RO and YP meaning more carbohydrate content after treatment.

To summarize, the typical absorption band that appears in RO and YP was similar, and there were no significant differences between them after different treatments.

3.5. Crystallinity Determination. The XRD patterns of the raw material, oxidized samples by TEMPO (TOWP), and nanofibrillated cellulose (TNFC) from red oak and yellow poplar are presented in Figures 2(a) and 2(b), respectively. The resultant Crystallinity index for those samples is displayed in Table 6.

All samples had diffraction peaks at $2 \theta=16.5^{\circ}$ and $22.5^{\circ}$, which is considered to represent the typical cellulose I pattern [38]. The crystallinity index (CI) of the original samples was 37 and $34.4 \%$ for RO and YP, respectively. After oxidation, the apparent crystallinity of samples increased to 61.7 and $59.8 \%$ in RO and YP, respectively, owing to the removal of hemicellulose and lignin. This increase was expected, but not that significant. Some artifacts in the measurement of CI might be affecting the results, but since the increase was similar for both species, the values were accepted. The crystallinity went through significant reduction upon the homogenization process to a degree of $39 \%$ in TNFC species of RO and YP, respectively. Mechanical fibrillation appears to affect importantly the final crystallinity of TNFC samples, but, once again, caution must be considered here because of possible artifacts associated with the measurements of crystallinity of TEMPOoxidized pulps. Some researchers determined a reduction in crystallinity after a high level homogenization of TEMPOoxidized pulps due to either breakage or peeling-off of the cellulose [9, 13, 39]. Even though differences in the crystallinity index after the TEMPO oxidation stage and after the fibrillation process were observed, the differences were similar between the two hardwood species in study.

3.6. Thermal Gravimetric Analysis. Thermogravimetric (TGA) and derivative thermogravimetric (DTG) analyses were performed to compare the thermal degradation characteristics of the untreated and chemomechanical treated RO and YP. Details of the major decomposition temperatures and the corresponding percentage of weight losses are summarized in Table 7. The thermal behaviour of lignocellulosic materials depends on their chemical composition, structure, degree of crystallinity, and the molecular interactions between the different macromolecules [40]. Between the temperatures of 150 and $500^{\circ} \mathrm{C}$, the degradation process begins in the cellulose, hemicellulose, and the associated linked water.

In the TGA curve represented by weight (\%) (Figure 3(a)), thermal degradation of untreated raw samples begins at temperatures 304.5 and $312^{\circ} \mathrm{C}\left(T_{\text {Onset }}\right)$, whereas in TEMPOoxidized NFCs the $T_{\text {onset }}$ began at 224 and $225^{\circ} \mathrm{C}$ for $\mathrm{RO}$ and YP, respectively. In the DTG curve represented by deriv. weight $\left(\% /{ }^{\circ} \mathrm{C}\right.$ ) (Figure $\left.3(\mathrm{~b})\right)$, both TEMPO-oxidized and untreated samples showed a prominent pyrolysis process, with a clear double step degradation for TNFC samples (stages I and II). The maximum weight loss was observed in the temperature ranges $230-290^{\circ} \mathrm{C}$ and $285-366^{\circ} \mathrm{C}$, respectively.

As shown in the DTG curves in Figure 3(b) the untreated $\mathrm{RO}$ showed a small broadening or shoulder at $285^{\circ} \mathrm{C}$ on the left side of the main peak $\left(366^{\circ} \mathrm{C}\right)$, which may have been due to the decomposition of hemicellulose as hemicelluloses has lower thermal stability than lignin and cellulose [41]. In the case of the untreated YP, the DTG curve showed a less sharp peak on the left side of the main peak, which may be explained by the lower content of hemicellulose. This probably resulted in better thermal properties for the untreated YP than RO (304.5 versus 312 in Table 7 for raw RO and raw YP, resp.) since the decomposition of hemicellulose begins at much lower temperatures, compared to cellulose [42]. The final major decomposition peak observed at the high temperature range $\left(300-400^{\circ} \mathrm{C}\right)$ is accounted for in the pyrolysis of cellulose. This peak was higher in YP compared to RO in both raw fibers and TNFC samples (stage II of Table 7) and might be explained by the fact that YP showed a higher cellulose content than RO by carbohydrate measurement (Table 3). As expected, the degradation temperatures of TEMPO-oxidized NFCs for both RO and YP were lower than those of untreated samples, because the carboxylic acid groups initiate thermal decomposition at lower temperatures [43]. These results are consistent with the results obtained from FTIR and XRD measurements. As presented in Table 7, the char residues (CY\%) from TNFC samples were higher than those of raw samples. The large amount of char residue form TEMPOoxidized NFCs is due to the high sodium ion which will hold carbonate, so the high sodium content after neutralization 
TABLE 8: Mechanical properties of transparent films of the oxidized cellulose fibrils.

\begin{tabular}{lccc}
\hline Samples & Tensile modulus $(\mathrm{Gpa})$ & Max tensile stress $(\mathrm{Mpa})$ & Strain at break (\%) \\
\hline TNFC $_{\mathrm{RO}}$ & $12.35 \pm 1.02$ & $129.8 \pm 16.36$ & $7.75 \pm 1.4$ \\
$\mathrm{TNFC}_{\mathrm{YP}}$ & $13.6 \pm 2.09$ & $135.15 \pm 14.2$ & $6.41 \pm 2.04$ \\
\hline
\end{tabular}

TABLE 9: Copper determination using EDX of hybrid material TNFC-CuNPs based on TNFC from Red oak and Yellow poplar (three repetitions).

\begin{tabular}{ll}
\hline Samples & $\mathrm{Cu}(\mathrm{wt} \%)$ \\
\hline TNFC $_{\mathrm{RO}}$ & $18.9 \pm 2.8$ \\
$\mathrm{TNFC}_{\mathrm{YP}}$ & $20.2 \pm 4.1$ \\
\hline
\end{tabular}

results in a high ash (char) content in of TEMPO treated pulps (TOWP). In summary, based on TGA analysis, TNFCs from YP and RO have similar thermal stability.

3.7. Morphology of the Treated and Untreated Samples. Figures 4(a) and 4(b) are SEM images of bleached samples of $\mathrm{RO}$ and YP, respectively. Before the analysis the samples were dried in a conventional laboratory oven at $103^{\circ} \mathrm{C} \pm 2^{\circ} \mathrm{C}$ overnight. The average in diameter for RO fiber was $9.16 \pm$ $1.06 \mu \mathrm{m}$ and $15.5 \pm 1.04 \mu \mathrm{m}$ for YP, according to the SEM images.

Figures 4(c) and 4(d) represent SEM images of TEMPOoxidized fibers (TOWP) of RO and YP, respectively. Before the analysis the samples were dried in a conventional laboratory oven at $103^{\circ} \mathrm{C} \pm 2^{\circ} \mathrm{C}$ overnight. The resultant average in diameter for TOWP of RO is of $7.99 \pm 1.75 \mu \mathrm{m}$ and $17.69 \pm$ $2.12 \mu \mathrm{m}$ for TOWP of YP. The TEMPO oxidation process has not affected the dry fiber diameters.

Figures 4(e) and 4(f) are SEM images of TEMPO nanofibrillated cellulose (TNFC) from RO and YP, respectively. Before the analysis the samples were dried using a solvent exchange process previously to a freeze drying stage [20]. The preparation method aims to produce a material with high specific surface area. As presented in both images a fibrillar and porous network structure resulted for both red oak and yellow poplar species. The magnification for these samples was different compared to the previous ones, to highlight the high porous structure resultant for both species after their mechanical fibrillation and drying processes.

In Figures 5(a) and 5(b) TEM images of TEMPO nanofibrillated cellulose (TNFC) from RO and YP, respectively, are presented. As mentioned earlier, the diameters of these TNFCs were measured from TEM images using the ImageJ Manipulation Program [21]. The average diameter for TNFC from RO resulted as $3.8 \pm 0.74 \mathrm{~nm}$ and as $3.6 \pm 0.85 \mathrm{~nm}$ for TNFC from YP. The maximum diameter was 5-6 nm with $6 \%$ distribution in both species.

The distribution of diameter percentages of nanofibrils is presented in Figures 5(c) and 5(d) for TNFC RO and TNFC YP, respectively. This information indicates that there are $10 \%$ more nanofibrils with diameters in the range of $3.0-4.0 \mathrm{~nm}$ for RO compared with $\mathrm{YP}$, and also $10 \%$ more nanofibrils with diameters in the range of 5.0-6.0 $\mathrm{nm}$ for RO compared to YP. No nanofibrils with diameters in the range $1.0-2.0 \mathrm{~nm}$ were found for RO. In the nanofibril diameter range between 2.0 and $3.0 \mathrm{~nm}$ YP resulted $14.5 \%$ higher than RO. The introduction of negative carboxyl groups on nanofibril surface generated strong repulsive forces, which resulted in separated individual nanofibrils with narrow diameter distribution [44].

3.8. Mechanical Properties of NFC Films. TNFC films of RO and YP were produced and their mechanical properties were measured. Ten randomly chosen films were used for these measurements. The average film thickness was 127 micrometers for both NFC samples.

The tensile modulus (modulus of elasticity or MOE) of the various NFC films was calculated based on the initial linear region of the stress-strain curve and is shown in Figure 6(a). $\mathrm{YP}$ and RO were shown to be very close in MOE (12.35 \pm $1.02 \mathrm{GPa}$ versus $13.6 \pm 2.09$ ) with no significant $p$ value. Previous studies by other groups showed that tensile modulus strongly depends on the crystallinity of nanofibrils as $[23,45,46]$. The results of MOE in both species were in accordance with XRD analysis by which both TNFC samples showed close range of crystallinity after homogenization (Table 6). The strain at break for the various NFC films also demonstrated no significant difference between films of RO $(7.75 \% \pm 1.4)$ compared to YP $(6.41 \% \pm 2.04)$ (Figure 6 (b) and Table 8).

The maximum tensile stress (strength) of films prepared from different NFCs is shown in Figure 6(c) and Table 8. It can be seen the TEMPO films from YP had almost the same mechanical strength with a small increase of approximately $135.15 \pm 14.2 \mathrm{MPa}$ compared to RO $(129.8 \pm 16.36 \mathrm{MPa})$. This difference is not significant according to the $t$-test ( $p$ value > 0.05).

Henriksson et al. (2008) [47] pointed out that the tensile strength, toughness, and strain to failure of nanofiber films correlate with the average molar mass of the nanofibers. Qing et al. (2013) [23] reported similar results from Eucalyptus TNFC samples, showing higher tensile strength of approximately $220 \mathrm{MPa}$ caused mainly because of the higher DP of the oxidized cellulose, while the crystallinity of their TNFC samples was in the range of our samples. Saito et al. (2009) [44] also reported that TEMPO/ $\mathrm{NaClO} / \mathrm{NaClO}_{2}$ system provides $\mathrm{CNF}$ with up to approximately 1.5 times higher tensile strength (312 MPa) compared to those CNF from TEMPO/ $\mathrm{NaBr} / \mathrm{NaClO}$, which was again attributed to the higher DP of the final CNF. Moreover, Rodionova et al. (2012) [8] reported that the final refining and homogenization process results in significantly higher defects and shorter lengths for hardwood nanofibers compared to softwood nanofibers; 
so, the correspondent tensile strengths of the softwood nanofiber films were significantly higher than the strengths of the hardwood nanofiber films.

3.9. Copper Determination. As mentioned earlier, samples of TNFC from red oak and yellow poplar after the copper synthesis step (TNFC-Cu) were characterized by Energy-Dispersive X-ray Analysis (EDX). The results show that both nanofibrillated hybrid materials (from red oak and yellow poplar) have similar copper weight percentage present after the synthesis process. This result can be attributed to the similar carboxylate content for both TNFC species and sites where copper is reduced from salts to the correspondent metallic state. This result is confirmed through the SEM analysis, presented in Figure 7, where the presence of copper is represented as crystals on the surface of TNFC-Cu from red oak. Similar pictures were found for yellow poplar. The presence of copper in the nanofibrillated hybrid material makes it possible to assume that the final hybrid material will possess antimicrobial properties as demonstrated in a previous research [48].

\section{Conclusions}

Underutilized woody biomass composed by red oak (Quercus rubra) and yellow poplar (Liriodendron tulipifera) was used for producing TEMPO nanofibrillated cellulose (TNFC) using a chemimechanical treatment. The morphological analysis performed by TEM on TNFC indicated a final average fibril width between 3 and $4 \mathrm{~nm}$ for both species. The carboxylate content after the TEMPO oxidation process resulted in approximately $0.8 \mathrm{mmol} / \mathrm{g}$ for both species. No difference in the lignin composition trend was observed after the pulping and bleaching process for both woody species; hemicellulose content was higher for red oak in all treated and untreated samples but showed no impact on the final morphology, carboxylate content, or mechanical properties of the final TNFC. Model films prepared from red oak and yellow poplar evidenced similar thermomechanical properties; however, the strength of the two species seemed to be lower than the values published elsewhere. The low strength of films achieved in this research is probably due to the reduced DP after the mechanical treatment. Overall, both TNFCs from red oak and yellow poplar presented the same capability to support metallic copper to be used as hybrid materials in thermoplastic films for applications in the packaging and medical/pharmacy fields.
Abbreviations
NFC: Nanofibrillated cellulose
TNFC: TEMPO nanofibrillated cellulose
TEMPO: 2,2,6,6-Tetramethylpiperidine-1-oxyl radical
XRD: X-ray diffraction
RO: $\quad$ Red oak
YP: $\quad$ Yellow poplar
TOWP: TEMPO-oxidized (bleached) wood pulp
TEM: Transmission electron microscopy
SEM: Scanning electron microscopy
DP: $\quad$ Degree of polymerization.

\section{Conflicts of Interest}

The authors declare that there are no conflicts of interest regarding the publication of this paper.

\section{Acknowledgments}

Funding for this work has been provided by NIFA McStennis WVA00098 "Efficient Utilization of Biomass for Biopolymers in Central Appalachia" and USDA NIFA Grant no. 2013-34638-21481 "Development of Novel Hybrid Cellulose Nanocomposite Film with Potent Biocide Properties Utilizing Low Quality Appalachian Hardwoods.” Special thanks are due to Changle Jiang, Ph.D. student in forest resources science, for performing the copper determination analysis on TNFCs (EDX-SEM).

\section{References}

[1] T. Saito, S. Kimura, Y. Nishiyama, and A. Isogai, "Cellulose nanofibers prepared by TEMPO-mediated oxidation of native cellulose," Biomacromolecules, vol. 8, no. 8, pp. 2485-2491, 2007.

[2] W. Jin, K. Singh, and J. Zondlo, "Pyrolysis kinetics of physical components of wood and wood-polymers using isoconversion method," Agriculture, vol. 3, no. 1, pp. 12-32, 2013.

[3] T. Pääkkönen, K. Dimic-Misic, H. Orelma, R. Pönni, T. Vuorinen, and T. Maloney, "Effect of xylan in hardwood pulp on the reaction rate of TEMPO-mediated oxidation and the rheology of the final nanofibrillated cellulose gel," Cellulose, vol. 23, no. 1, pp. 277-293, 2016.

[4] Q. Meng, H. Li, S. Fu, and L. A. Lucia, "The non-trivial role of native xylans on the preparation of TEMPO-oxidized cellulose nanofibrils," Reactive and Functional Polymers, vol. 85, pp. 142150, 2014.

[5] K. Syverud, G. Chinga-Carrasco, J. Toledo, and P. G. Toledo, "A comparative study of Eucalyptus and Pinus radiata pulp fibres as raw materials for production of cellulose nanofibrils," Carbohydrate Polymers, vol. 84, no. 3, pp. 1033-1038, 2011.

[6] I. Siró and D. Plackett, "Microfibrillated cellulose and new nanocomposite materials: a review," Cellulose, vol. 17, no. 3, pp. 459-494, 2010.

[7] A. Isogai, T. Saito, and H. Fukuzumi, "TEMPO-oxidized cellulose nanofibers," Nanoscale, vol. 3, no. 1, pp. 71-85, 2011.

[8] G. Rodionova, Ø. Eriksen, and Ø. Gregersen, “TEMPO-oxidized cellulose nanofiber films: effect of surface morphology on water resistance," Cellulose, vol. 19, no. 4, pp. 1115-1123, 2012.

[9] I. Besbes, M. R. Vilar, and S. Boufi, "Nanofibrillated cellulose from Alfa, Eucalyptus and Pine fibres: preparation, characteristics and reinforcing potential," Carbohydrate Polymers, vol. 86, no. 3, pp. 1198-1206, 2011.

[10] F. W. Brodin and H. Theliander, "A comparison of softwood and birch kraft pulp fibers as raw materials for production of TEMPO-oxidized pulp, MFC and superabsorbent foam," Cellulose, vol. 20, no. 6, pp. 2825-2838, 2013.

[11] G. Rodionova, T. Saito, M. Lenes et al., "TEMPO-Mediated Oxidation of Norway Spruce and Eucalyptus Pulps: Preparation and Characterization of Nanofibers and Nanofiber Dispersions," Journal of Polymers and the Environment, vol. 21, no. 1, pp. 207-214, 2013. 
[12] W. Stelte and A. R. Sanadi, "Preparation and characterization of cellulose nanofibers from two commercial hardwood and softwood pulps," Industrial \& Engineering Chemistry Research, vol. 48, no. 24, pp. 11211-11219, 2009.

[13] T. Zimmermann, N. Bordeanu, and E. Strub, "Properties of nanofibrillated cellulose from different raw materials and its reinforcement potential," Carbohydrate Polymers, vol. 79, no. 4, pp. 1086-1093, 2010.

[14] C. Jiang, G. S. Oporto, T. Zhong, and J. Jaczynski, “TEMPO nanofibrillated cellulose as template for controlled release of antimicrobial copper from PVA films," Cellulose, vol. 23, no. 1, pp. 713-722, 2016.

[15] T. Zhong, G. S. Oporto, J. Jaczynski, and C. Jiang, "Nanofibrillated cellulose and copper nanoparticles embedded in polyvinyl alcohol films for antimicrobial applications," BioMed Research International, vol. 2015, Article ID 456834, 2015.

[16] J. Wu, M. Sperow, and J. Wang, "Economic feasibility of a woody biomassbased ethanol plant in central Appalachia," Journal of Agricultural and Resource Economics, vol. 35, no. 3, pp. 522-544, 2010.

[17] P. M. Jacobson, Properties of Polyvinyl Alcohol Nanocomposites Reinforced with Cellulose Nanocrystals of Red Oak Residues, West Virginia University, 2011.

[18] M. W. Davis, "A rapid modified method for compositional carbohydrate analysis of lignocellulosics by high $\mathrm{pH}$ anionexchange chromatography with pulsed amperometric detection (HPAEC/PAD)," Journal of Wood Chemistry and Technology, vol. 18, no. 2, pp. 235-352, 1998.

[19] L. Segal, J. Creely, A. Martin, and C. Conrad, "An empirical method for estimating the degree of crystallinity of native cellulose using the x-ray diffractometer," Textile Research Journal, vol. 29, no. 10, pp. 786-794, 1959.

[20] T. Zhong, G. S. Oporto, Y. Peng, X. Xie, and D. J. Gardner, "Drying cellulose-based materials containing copper nanoparticles," Cellulose, vol. 22, no. 4, pp. 2665-2681, 2015.

[21] T. Ferreira and W. Rasband, ImageJ User Guide/IJ 1.46r, Research Services Branch Web, http://imagej.nih.gov/ij/docs/ guide/user-guide.pdf.

[22] Y. Qing, R. Sabo, Y. Wu, J. Zhu, and Z. Cai, "Self-assembled optically transparent cellulose nanofibril films: effect of nanofibril morphology and drying procedure," Cellulose, vol. 22, no. 2, pp. 1091-1102, 2015.

[23] Y. Qing, R. Sabo, J. Y. Zhu, U. Agarwal, Z. Cai, and Y. Wu, "A comparative study of cellulose nanofibrils disintegrated via multiple processing approaches," Carbohydrate Polymers, vol. 97, no. 1, pp. 226-234, 2013.

[24] S. Iwamoto, K. Abe, and H. Yano, "The effect of hemicelluloses on wood pulp nanofibrillation and nanofiber network characteristics," Biomacromolecules, vol. 9, no. 3, pp. 1022-1026, 2008.

[25] J. Li, O. Sevastyanova, and G. Gellerstedt, "The relationship between kappa number and oxidizable structures in bleached kraft pulps," Journal of Pulp and Paper Science (JPPS), vol. 28, pp. 262-266, 2002.

[26] W. Chen, H. Yu, and Y. Liu, "Preparation of millimeter-long cellulose I nanofibers with diameters of $30-80 \mathrm{~nm}$ from bamboo fibers," Carbohydrate Polymers, vol. 86, no. 2, pp. 453-461, 2011.

[27] J. P. S. Morais, M. de Freitas Rosa, M. M. S. De Souza Filho, L. D. Nascimento, D. M. Do Nascimento, and A. R. Cassales, "Extraction and characterization of nanocellulose structures from raw cotton linter," Carbohydrate Polymers, vol. 91, no. 1, pp. 229-235, 2013.
[28] P. K. Poddar, A. Gupta, S. S. Jamari, N. S. Kim, T. A. Khan, S. Sharma et al., "Synthesis of nanocellulose from rubberwood fibers via ultrasonication combined with enzymatic and chemical pretreatments," Asian Journal of Applied Sciences, vol. 3, 2015.

[29] R. Wicaksono, K. Syamsu, I. Yuliasih, and M. Nasir, "Cellulose nanofibers from cassava bagasse: characterization and application on tapioca-film," Chemistry and Materials Research, vol. 3, no. 13, pp. 79-87, 2013.

[30] W. Wulandari, A. Rochliadi, and I. Arcana, "Nanocellulose prepared by acid hydrolysis of isolated cellulose from sugarcane bagasse," in IOP Conference Series: Materials Science and Engineering, IOP Publishing, 2016.

[31] A. Alemdar and M. Sain, "Isolation and characterization of nanofibers from agricultural residues-wheat straw and soy hulls," Bioresource Technology, vol. 99, no. 6, pp. 1664-1671, 2008.

[32] X. F. Sun, F. Xu, R. C. Sun, P. Fowler, and M. S. Baird, "Characteristics of degraded cellulose obtained from steamexploded wheat straw," Carbohydrate Research, vol. 340, no. 1, pp. 97-106, 2005.

[33] M. Jonoobi, K. O. Niska, J. Harun, and M. Misra, "hemical composition, crystallinity, and thermal degradation of bleached and unbleached kenaf bast (Hibiscus cannabinus) pulp and nanofibers," BioResources, vol. 4, no. 2, pp. 626-639, 2009.

[34] M. Sain and S. Panthapulakkal, "Bioprocess preparation of wheat straw fibers and their characterization," Industrial Crops and Products, vol. 23, no. 1, pp. 1-8, 2006.

[35] M. Le Troedec, D. Sedan, C. Peyratout et al., "Influence of various chemical treatments on the composition and structure of hemp fibres," Composites A: Applied Science and Manufacturing, vol. 39, no. 3, pp. 514-522, 2008.

[36] N. S. Lani, Ngadi N., A. Johari, and M. Jusoh, "Isolation, characterization, and application of nanocellulose from oil palm empty fruit bunch fiber as nanocomposites," Journal of Nanomaterials, vol. 2014, Article ID 702538, 9 pages, 2014.

[37] D. Liu, Y. Liu, and G. Sui, "Synthesis and properties of sandwiched films of epoxy resin and graphene/cellulose nanowhiskers paper," Composites Part A: Applied Science and Manufacturing, vol. 84, pp. 87-95, 2016.

[38] Y. Nishiyama, P. Langan, and H. Chanzy, "Crystal structure and hydrogen-bonding system in cellulose $\mathrm{I} \beta$ from synchrotron $\mathrm{X}$-ray and neutron fiber diffraction," Journal of the American Chemical Society, vol. 124, no. 31, pp. 9074-9082, 2002.

[39] Q. Q. Wang, J. Y. Zhu, R. Gleisner, T. A. Kuster, U. Baxa, and S. E. McNeil, "Morphological development of cellulose fibrils of a bleached eucalyptus pulp by mechanical fibrillation," Cellulose, vol. 19, no. 5, pp. 1631-1643, 2012.

[40] S. Maiti, J. Jayaramudu, K. Das et al., "Preparation and characterization of nano-cellulose with new shape from different precursor," Carbohydrate Polymers, vol. 98, no. 1, pp. 562-567, 2013.

[41] C. J. Chirayil, J. Joy, L. Mathew, M. Mozetic, J. Koetz, and S. Thomas, "Isolation and characterization of cellulose nanofibrils from Helicteres isora plant," Industrial Crops and Products, vol. 59, pp. 27-34, 2014.

[42] M. M. Kabir, H. Wang, K. T. Lau, and F. Cardona, "Effects of chemical treatments on hemp fibre structure," Applied Surface Science, vol. 276, pp. 13-23, 2013.

[43] B. Deepa, E. Abraham, N. Cordeiro et al., "Utilization of various lignocellulosic biomass for the production of nanocellulose: a comparative study," Cellulose, vol. 22, no. 2, pp. 1075-1090, 2015. 
[44] T. Saito, M. Hirota, N. Tamura et al., "Individualization of nanosized plant cellulose fibrils by direct surface carboxylation using TEMPO catalyst under neutral conditions," Biomacromolecules, vol. 10, no. 7, pp. 1992-1996, 2009.

[45] H. Fukuzumi, T. Saito, and A. Isogai, "Influence of TEMPOoxidized cellulose nanofibril length on film properties," Carbohydrate Polymers, vol. 93, no. 1, pp. 172-177, 2013.

[46] A. Retegi, N. Gabilondo, C. Peña, R. Zuluaga, C. Castro, P. Gañan et al., "Bacterial cellulose films with controlled microstructure-mechanical property relationships," Cellulose, vol. 17, no. 3, pp. 661-669, 2010.

[47] M. Henriksson, L. A. Berglund, P. Isaksson, T. Lindström, and T. Nishino, "Cellulose nanopaper structures of high toughness," Biomacromolecules, vol. 9, no. 6, pp. 1579-1585, 2008.

[48] T. Zhong, G. S. Oporto, J. Jaczynski, A. Tesfai, and J. Armstrong, "Antimicrobial properties of the hybrid copper nanoparticlescarboxymethyl cellulose," Wood and Fiber Science, vol. 45, no. 2, pp. 1-8, 2013. 

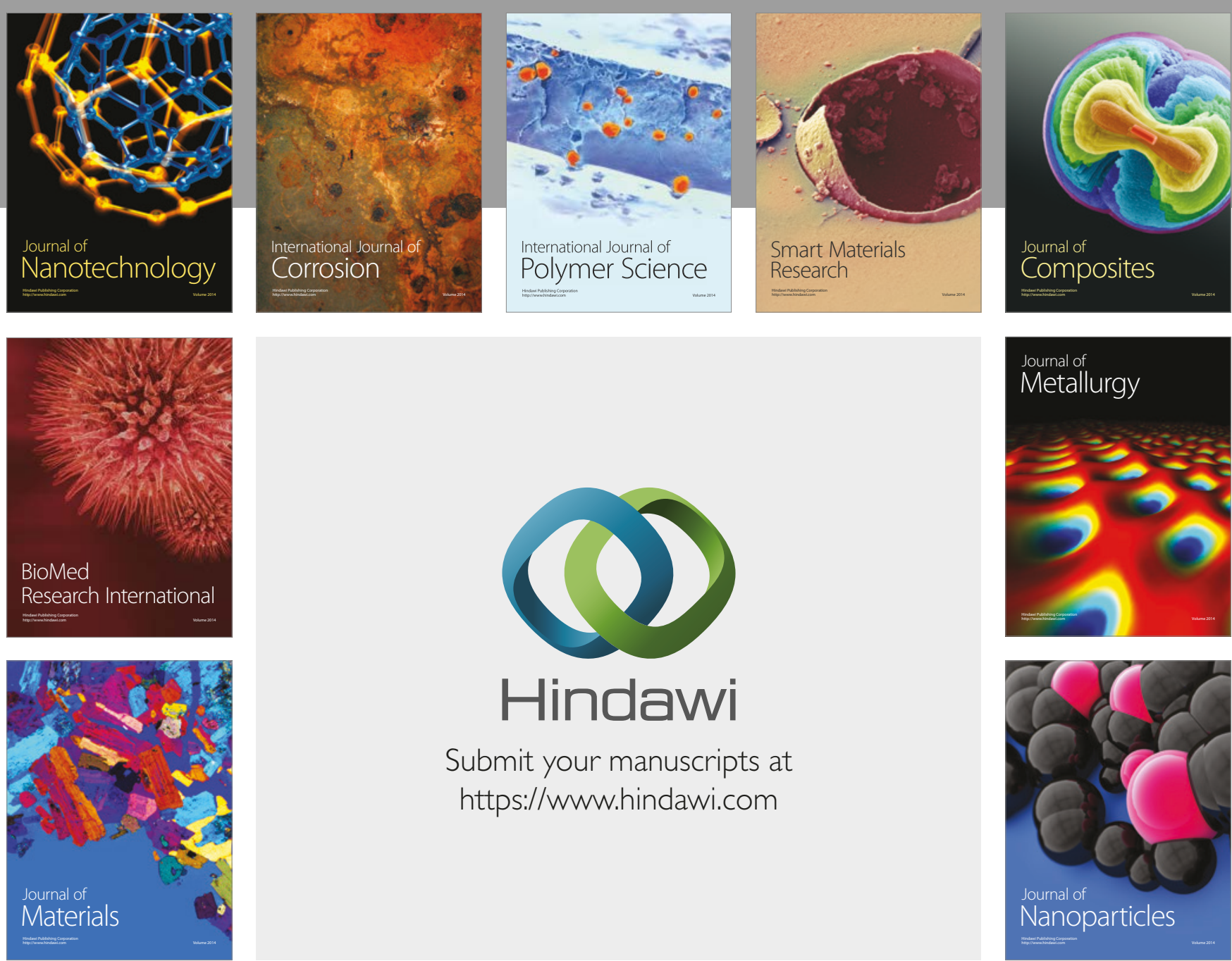

\section{Hindawi}

Submit your manuscripts at

https://www.hindawi.com
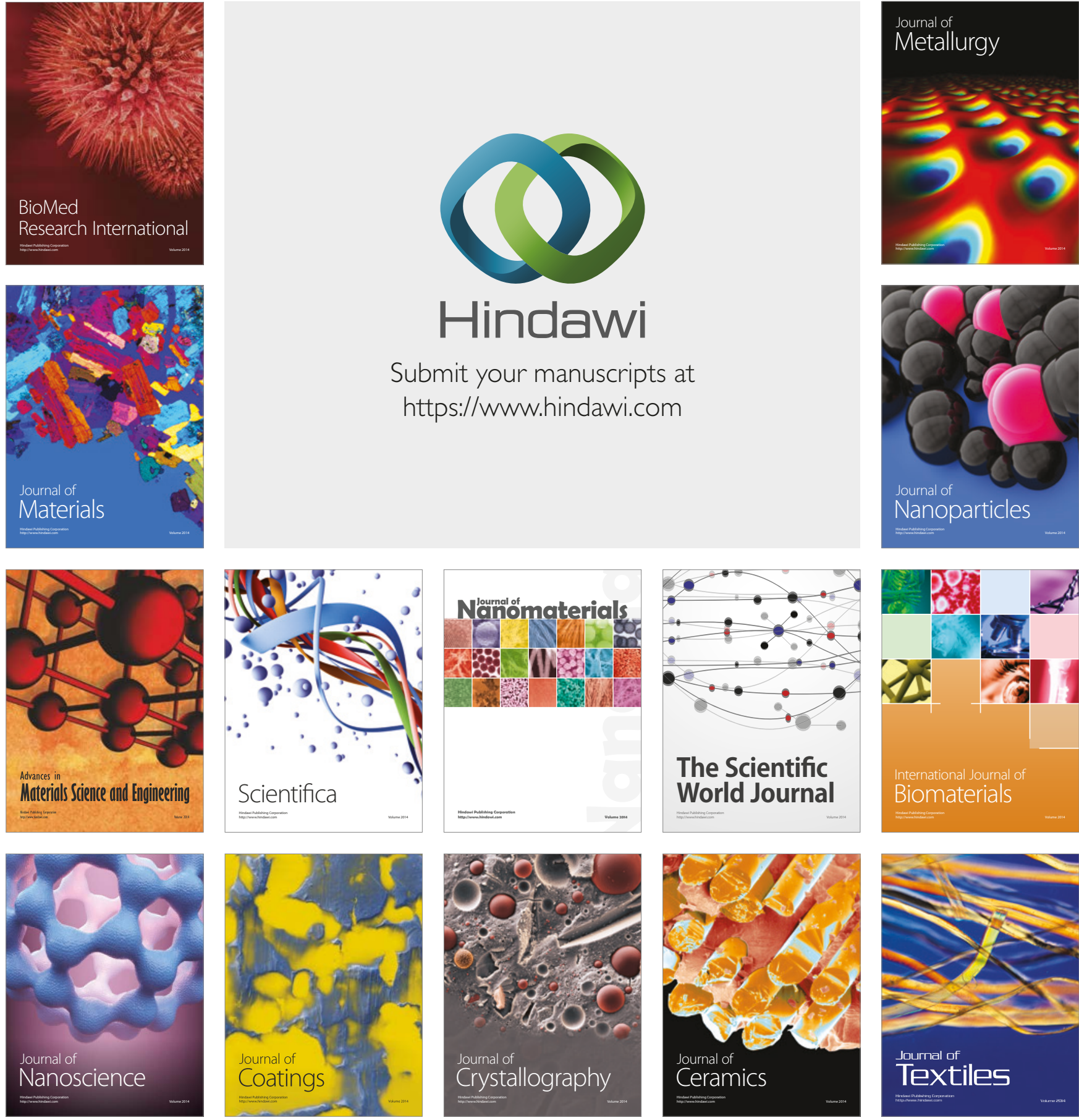

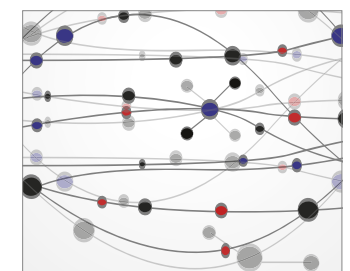

The Scientific World Journal
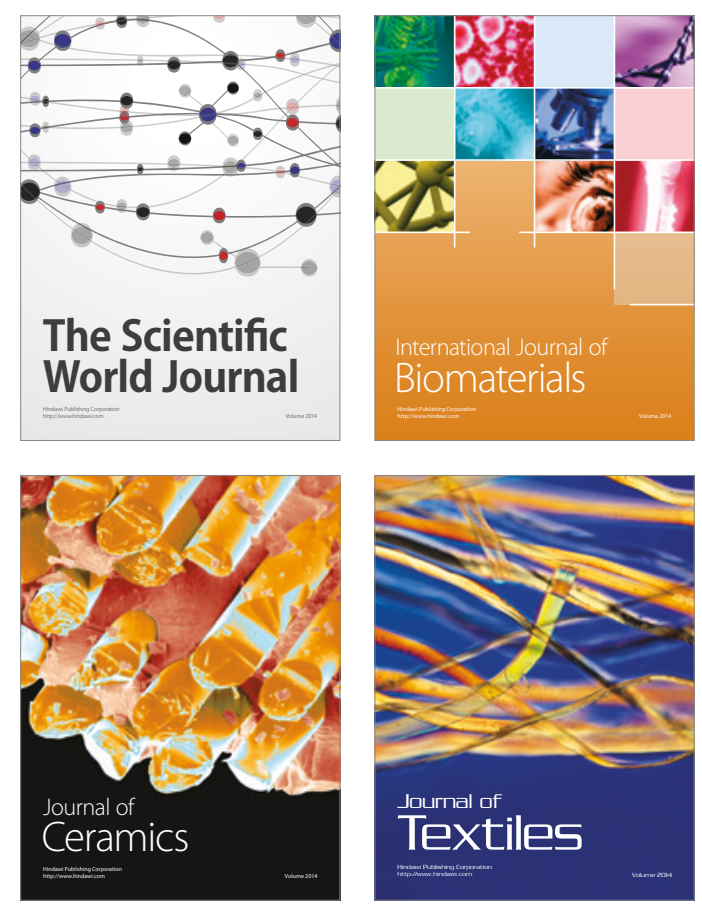